\section{REPORT OF COMMITTEE II ON PERMISSIBLE DOSE FOR INTERNAL RADIATION (1959)}

Published for International Commission on Radiological Protection by Pergamon Press Ltd. Pp. xxxii +233 . 1960. 30s.

This volume supersedes the previous I.C.R.P. Recommendations of December 1954, which were published as the well-known Supplement 6 of the British Journal of Radiology. There are significant differences from the earlier data, and also differences from the more up-to-date M.O.H. and M.R.C. - Code of Practice for the Protection of Persons Exposed to Ionising Radiations' (H.M.S.O., June 1957). It is likely that the revised 'Code' at present being prepared by the M.O.H. and M.R.C. will tend to follow the new I.C.R.P. report.

This volume reprints entirely the 18-page ' Recommendations of the I.C.R.P. (adopted September 9, 1958) ' which was published separately by Pergamon Press in 1959, so that the present volume includes all the current I.C.R.P. recommendations. This section states the basic concepts of the recommendations, and gives the recommended maximum permissible limits of dose. It is worth recapitulating that the basis of the new M.P.L.s is somewhat different from the 1954 limits and from those given in the 1957 ' Code of Practice '. The formula $\mathrm{D}=5(\mathrm{~N}-18)$ is officially introduced, where $D$ is the maximum permissible tissue dose in rems and $\mathbf{N}$ is the age in years. A virtual yearly M.P.L. of 5 rems is therefore recommended, instead of a 10-year limit of 50 rems. Secondly, instead of a weekly permissible dose, the smallest single unit of M.P.L. is now the $13-$ week dose (which is similar in magnitude to the previously recommended 13 -week M.P.L.s). These changes give greater flexibility in day-to-day work, while introducing a stricter year-to-year control. The M.P.L. for skin has been reduced by the large factor of 2.5 , to $0.6 \times 13 \mathrm{rem}$ per 13 weeks, and this dose applies to the surface of the skin instead of to a depth of $7 \mathrm{mg} . / \mathrm{cm} .^{2}$

The internal M.P.L.s are based on $0.1 \mathrm{rem} /$ week for the whole body or gonads (averaged over a year), $0.6 \mathrm{rem} / \mathrm{week}$ to the skin and thyroid, and 0.3 rem/week to all other soft tissues, averaged over 13 weeks. These values are for non-bone-seeking radionuclides. For bone-seekers, however, such as ${ }^{\circ 0} \mathrm{Sr}$ and ${ }^{239} \mathrm{Pu}$, etc., estimates are based on comparisons with a body burden of $0.1 \mu \mathrm{c}$. of ${ }^{226} \mathrm{Ra}$. A full discussion of the reasons for using these two different criteria is given on pages 11 to 15 . A safety factor of 10 is recommended, as before, for prolonged exposure of a large population.

The number of radionuclides listed in Supple ment 6 has been increased by a factor of about three? A greater number of alternative choices for the critical organ is offered. New biological data have resulted in modifications of some maximum pero missible body burdens and concentrations. All the physical parameters have also been reviewed. $\operatorname{Re}$ 윽 finements in calculations for the exposure of thegastrointestinal tract and for chains of radionuclides in the body have also resulted in some new values? It is claimed that the most important findings published in 1957 and early $195^{8}$ have been reviewed.

Examples of reductions in body burdens inclugleo tritium (1 mc. instead of 10 $\mathrm{mc}$.), ${ }^{32} \mathrm{P}$ (now 6 cㅇㅇ instead of $10 \mu \mathrm{c}$.), ${ }^{35} \mathrm{~S}$ (now $90 \mu \mathrm{c}$. instead of $300 \mu \mathrm{c}$ ) ${ }^{24} \mathrm{Na}$ (now $7 \mu \mathrm{c}$. instead of ${ }_{15} \mu \mathrm{c}$.), ${ }^{42} \mathrm{~K}$ (now $10{ }_{\mu \mathrm{co}}$ instead of $21 \mu \mathrm{c}$.), and ${ }^{137} \mathrm{Cs}$ (now $30 \mu \mathrm{c}$. instead of $98 \mu \mathrm{c}$.). Examples of increases in body burdenso include ${ }^{90} \mathrm{Sr}$ (now $2 \mu \mathrm{c}$. instead of $\mathrm{I} \mu \mathrm{c}$.), ${ }^{45} \mathrm{Ca}$ (nowő $30 \mu \mathrm{c}$. instead of $14 \mu \mathrm{c}$.), and ${ }^{131} \mathrm{I}$ (now $0.7 \mu \mathrm{c}_{\mathscr{\Omega}}^{\mathbb{D}}$ instead of $0.6 \mu \mathrm{c}$.). Some examples of changes due to new physiological data are that the critical organ for ${ }^{35} \mathrm{~S}$ is now given as the testis, whereas previously it was considered to be the skin; and that the body burden for ${ }^{137} \mathrm{Cs}$ would be $50 \mu \mathrm{c}$. in muscle, but is . $30 \mu \mathrm{c}$. in the total body.

A serious limitation is that the chemical form in which the radionuclide is ingested is not generally? specified. The tables are not therefore directly useful in calculating M.P.L.s of labelled organic chemicals to be used in tracer studies, for example $\bar{乛}$

It is interesting that the power function model is discussed in an appendix as an alternative method of estimating the body burden for certain long-lived radionuclides. The data in the tables are expressed as before, in terms of the exponential or compart $N$ ment model for retention and elimination, but the M.P.L. and body burden values listed in the tableso were selected after careful consideration of thew values obtained by use of both models.

The layout of the tables has been improved fo easier reference. Maximum permissible concentra tions are given both for a 40-hour week and an r68-hour week. The index includes a numbered list of equations, which is an excellent idea in a standard reference work of this kind. 